\title{
INSULIN-TRANSFERRIN-SELENIUM PREVENT HUMAN CHONDROCYTE DEDIFFERENTIATION AND PROMOTE THE FORMATION OF HIGH QUALITY TISSUE ENGINEERED HUMAN HYALINE CARTILAGE
}

\author{
K.H. Chua ${ }^{1}$, B.S. Aminuddin ${ }^{3}$, N.H. Fuzina ${ }^{2}$ and B.H.I. Ruszymah ${ }^{1}$ \\ Department of Physiology, Faculty of Medicine, Universiti Kebangsaan Malaysia, and Tissue Engineering \\ Laboratory, Hospital Universiti Kebangsaan Malaysia ${ }^{1}$; and the Animal Unit, Institute of Medical Research \\ Malaysia, Kuala Lumpur²; and the Ear Nose \& Throat Consultant Clinic, Ampang Puteri Specialist Hospital \\ Malaysia, Selangor ${ }^{3}$, Malaysia.
}

\begin{abstract}
This study was to investigate the effects of InsulinTransferrin-Selenium (ITS) on the proliferation and quantitative gene expression of adult human nasal septum chondrocytes in monolayer culture expansion and the formation of tissue engineered hyaline cartilage. Effects of ITS on human nasal septum chondrocytes monolayer culture expansion and gene expression were evaluated in various culture media either added with $2 \%$ fetal bovine serum (FBS) or $1 \mathrm{ng} / \mathrm{mL}$ basic fibroblast growth factor plus $1 \mathrm{ng} / \mathrm{mL}$ transforming growth factor or both serum and growth factors supplementation in comparison with medium added with $10 \%$ FBS. Chondrocytes cultured in medium added with $2 \%$ fetal bovine serum and growth factors either supplemented with or without ITS were then mixed with pluronic F-127 hydrogel for in vivo tissue engineered cartilage formation in nude mice model. Engineered tissues were removed after 8 weeks of implantation and evaluated with histological staining, immunohistochemistry, transmission electron microscopy and quantitative gene expression analysis. ITS promoted human chondrocytes proliferation and reduced chondrocytes dedifferentiation in media supplemented with serum and growth factors. ITS with $2 \%$ FBS and growth factors provided 15 -fold increased in chondrocytes number by the end of the culture period compared to the standard culture medium used in chondrocytes culture (medium added with 10\% FBS). Engineered tissue resulted from ITS supplementation demonstrated higher quality of cartilage formation. In conclusion, our study has demonstrated the benefits of ITS supplementation in human chondrocytes monolayer culture and tissue engineering cartilage formation.
\end{abstract}

Key Words: Tissue engineering, Insulin-TransferrinSelenium, human nasal septum chondrocytes, monolayer expansion, hydrogel, hyaline cartilage, transforming growth factor, basic fibroblast growth factor, quantitative gene expression.

Address for correspondence:

Ruszymah Binti Haji Idrus, MD, PhD

Department of Physiology, Faculty of Medicine

Universiti Kebangsaan Malaysia

Jalan Raja Muda Abdul Aziz

50300 Kuala Lumpur

Malaysia.

Telephone: 603-40405428

Fax: 603-26939687

E-mail: ruszy@medic.ukm.my

\section{Introduction}

Human nasal septum cartilage is a good starting material for tissue engineering in constructing a new autologous graft for head and neck reconstructive surgery. This cartilage has superior mechanical integrity compared to auricular cartilage and it is easily accessible by the surgeons in a sterile manner with minimum morbidity. Previous study has shown that nasal septum cartilage is high in cell density and chondrocytes with excellent proliferation capacity can be isolated from a broad range of human age (Rotter et al., 2001). Since only a small amount of cartilage can be harvested without inducing morbidity at the donor site, this limited number of isolated chondrocytes need to be culture-expanded before a clinical size engineered tissue can be made. The number of chondrocytes can be increased by monolayer culture, direct seeding into resorbable polyglycolic/polylactic acid polymer scaffolds or in three-dimensional alginate encapsulation system (Homicz et al., 2003). Homicz et al. (2003) has demonstrated that human septal chondrocytes were most effectively culture expanded in monolayer system compared to alginate or resorbable polymer scaffold. Large number of chondrocytes can be obtained in a short period of time with monolayer culture system. However, chondrocytes cultured in monolayer have a tendency to dedifferentiate due to the cytoskeleton modification in two-dimensional culture environment (Loty et al., 2000). Study by Homicz et al. (2002) also showed that serial expanded human septal chondrocytes gradually dedifferentiated by reducing the production on type II collagen in monolayer culture. Chondrocytes with dedifferentiated characteristics may limit the mechanical stability of neocartilage constructed and resulted in the formation of an inferior quality engineered cartilage.

Previous studies have shown that by encapsulating the dedifferentiated human auricular chondrocytes in alginate beads in the in vitro culture system, the culture expanded chondrocytes can redifferentiate by increasing the production of type II collagen (van Osch et al., 2001; Mandl et al., 2002). These results showed that, threedimensional environment can significantly improved the redifferentiation capacity of human chondrocytes. Nevertheless, it will be very beneficial if human chondrocytes can be expanded in monolayer culture whilst remaining its differentiated property.

The combination of insulin-transferrin-selenium (ITS) has been added into the alginate beads culture system to increase the event of redifferentiation in expanded chondrocytes (van Osch et al., 2001; Mandl et al., 2002). However, the role of ITS was not clearly explained in the 
experiment. In addition to that, ITS has not been investigated in human nasal septum chondrocytes monolayer culture for the ability of retaining the differentiated characters of isolated chondrocytes.

Studies have shown that serum provides growth promoting factors (Choi et al., 1980) as well as inhibitors on human cells proliferation (Harrington and Godman, 1980). The regulatory effects of ITS in human chondrocytes monolayer culture supplemented with serum was also not been investigated in previous studies. ITS may enhance the growth promoting effects of serum and reduce the inhibitor action in chondrocyte culture. Proliferation of chondrocytes can also be accelerated by growth factors supplementation in the medium. For example, basic fibroblast growth factor and transforming growth factor were previously showed to promote the proliferation of chondrocytes (Pei et al., 2002). Since recently, transforming growth factor beta 2 (TGF- $\beta 2$ ) was showed to be more potent as mitotic agent compared to other member in the family for human articular chondrocyte culture (Olney et al., 2004), TGF- $\beta 2$ was used as growth factor in this study. Whether ITS will react in synergistic or antagonistic with other growth factors in the culture medium is still unclear at the moment.

Our objectives in this study were to investigate the effects of ITS on human nasal septum chondrocytes monolayer culture expansion and quantitative gene expression for serial passages in various culture media. Interaction of ITS with serum was evaluated with $2 \%$ fetal bovine serum supplementation into the culture medium. Same lot of serum was used in the study to eliminate the variation of biochemical properties in the serum. Interaction of ITS with growth factors $(1 \mathrm{ng} / \mathrm{mL}$ basic fibroblast growth factor plus $1 \mathrm{ng} / \mathrm{mL}$ transforming growth factor) was evaluated either with or without $2 \%$ serum supplementation. Culture medium supplemented with $10 \%$ fetal bovine serum was used in this study as control medium since most of the chondrocytes studies were referred this as standard medium for chondrocytes culture. Real-time PCR was used to quantify the expression of genes encoding the cartilage extra-cellular matrixes (type II collagen and aggrecan core protein), chondrocytes dedifferentiation (type I collagen) and chondrocytes hypertrophy (type X collagen).

In order to evaluate the effects of ITS on the quality of tissue engineered cartilage, a culture medium which can provide high number of cultured chondrocytes was selected for large scale culture. This medium was either supplemented with or without ITS in the large scale culture system for tissue engineered cartilage formation. The cultured chondrocytes were then harvested and suspended in a co-polymer of $30 \%$ polypropylene and $70 \%$ polyethylene pluronic F-127 for in vivo implantation. This hydrogel has been proven in other studies as a better biomaterial for minimizing the inflammatory response in immunocompetent animal models (Cao et al., 1998; Saim et al., 2000).
Table 1. Supplements to the human nasal septum chondrocytes culture medium

\begin{tabular}{cc}
\hline Group & Supplements \\
\hline A & $2 \%$ FBS \\
B & ITS \\
C & $2 \%$ FBS + ITS \\
D & $1 \mathrm{ng} / \mathrm{mL}$ bFGF $+1 \mathrm{ng} / \mathrm{mL}$ TGF- $\beta 2$ \\
E & $1 \mathrm{ng} / \mathrm{mL}$ bFGF $+1 \mathrm{ng} / \mathrm{mL}$ TGF- $\beta 2+2 \%$ FBS \\
F & $\operatorname{lng} / \mathrm{mL}$ bFGF $+1 \mathrm{lng} / \mathrm{mL}$ TGF- $\beta 2+$ ITS \\
G & $1 \mathrm{ng} / \mathrm{mL}$ bFGF $+1 \mathrm{ng} / \mathrm{mL}$ TGF- $\beta 2+$ ITS $+2 \%$ FBS \\
H & $10 \%$ FBS \\
\hline
\end{tabular}

Note:

FBS - fetal bovine serum (Gibco)

ITS $-10 \mu \mathrm{g} / \mathrm{mL}$ insulin $+5.5 \mu \mathrm{g} / \mathrm{mL}$ transferrin $+6.7 \mathrm{ng} /$

$\mathrm{mL}$ sodium selenite (Gibco)

bFGF - Basic fibroblast growth factor (Gibco)

TGF-beta 2 - Transforming growth factor beta 2 (Sigma, St. Louis. MO)

\section{Materials and Methods}

\section{Human Nasal Septum Chondrocytes Isolation}

Nasal septum cartilage was obtained from six consented patients aged range from 25 to 46 years after elective septoplasty. These specimens would usually be discarded and their used in the study has been approved by the Ethical Committee of Medical Faculty, Universiti Kebangsaan Malaysia. Each cartilage was cleaned from perichondrium, minced into small pieces $\left(1 \mathrm{~mm}^{3}\right)$, washed with phosphate buffer saline (PBS; pH7.2; Gibco, Grand Island, NY) containing $100 \mathrm{U} / \mathrm{mL}$ of penicillin (Gibco), $100 \mu \mathrm{g} / \mathrm{mL}$ of streptomycin (Gibco) and $0.25 \mu \mathrm{g} / \mathrm{mL}$ of amphotericin B (Gibco) and digest with $0.6 \%$ collagenase II (Gibco) at $37^{\circ} \mathrm{C}$ for 12 hours. After digestion, suspension containing isolated chondrocytes was centrifuged at $6,000 \mathrm{rpm}$ for 5 minutes. The resulting cell pellet was washed twice with PBS to remove remained digestive enzyme before being resuspended in PBS for total cell quantification with hemocytometer (Weber Scientific International Ltd. Middlx, England). Viability of chondrocytes was determined with trypan blue vital dye exclusion test (Gibco).

\section{Chondrocytes Monolayer Culture}

Isolated chondrocytes were seeded in six-well tissue culture plate (Falcon, Franklin Lakes, NJ) with a density of 5,000 cells $/ \mathrm{cm}^{2}$ in a equal volume mix of Ham's F12 medium and Dulbecco's Modified Eagle Medium (F12:DMEM; Gibco) supplemented with various factors in eight study groups as shown in table 1. Each culture medium also contained 200mM L-glutamine, $100 \mathrm{U} / \mathrm{mL}$ of penicillin, $100 \mu \mathrm{g} / \mathrm{mL}$ of streptomycin, $0.25 \mu \mathrm{g} / \mathrm{mL}$ of amphotericin B (Gibco) and $50 \mu \mathrm{g} / \mathrm{mL}$ of ascorbic acid (Sigma). All cultures were maintained in $5 \% \mathrm{CO}_{2}$ incubator (Jouan, Duguay Trouin, $\mathrm{SH}$ ) at $37^{\circ} \mathrm{C}$ with culture medium 
Table 2. Description of primer sequences used in real-time PCR for quantitative gene expression analysis

\begin{tabular}{l|l|l|c}
\hline \multicolumn{1}{c|}{ Gene } & \multicolumn{1}{c|}{ Access no. } & \multicolumn{1}{c|}{ Primer $\mathbf{5}^{\prime} \rightarrow \mathbf{3}^{\prime}$} & PCR product (bp) \\
\hline GAPDH & BC020308 & $\begin{array}{l}\text { F: tce ctg age tga acg gga ag } \\
\text { R: gga gga gtg ggt gtc gct gt }\end{array}$ & 217 \\
\hline Type I collagen & NM_000088 & $\begin{array}{l}\text { F: agg gct cca acg aga tcg aga tcc g } \\
\text { R: tac agg aag cag aca ggg cca acg }\end{array}$ & 222 \\
\hline Type II collagen & NM_001844 & $\begin{array}{l}\text { F: cta tct gga cga age age tgg ca } \\
\text { R: atg ggt gca atg tca atg atg g }\end{array}$ & 209 \\
\hline Type X collagen & NM_000493 & $\begin{array}{l}\text { F: agc cag ggt tgc cag gac ca } \\
\text { R: ttt tcc cac tcc agg agg gc }\end{array}$ & 385 \\
\hline $\begin{array}{l}\text { Aggrecan core } \\
\text { protein }\end{array}$ & NM_001135 & $\begin{array}{l}\text { F: cac tgt tac cge cac ttc cc } \\
\text { R: acc agc gga agt cce ctt cg }\end{array}$ & 183 \\
\hline
\end{tabular}

changed twice a week. Cell morphologic feature was examined everyday by inverted light microscope (Olympus, Shinjuku-ku, Tokyo). Chondrocytes at primary culture (P0) were grown until confluent and then released from culture plate using $0.05 \%$ trypsin-EDTA (Gibco). Harvested chondrocytes were washed and re-suspended in PBS for total cell number and viability determination using hemocytometer (Weber Scientific International Ltd). Then, cultured chondrocytes from each medium were passage three times (P1, P2 and P3) with the same cell density, culture medium and growth environment. Chondrocytes growth rate (average increase of chondrocyte number in one day $/ \mathrm{cm}^{2}$ ), number of cell doubling and viability in different groups were calculated for statistical analysis.

\section{Total RNA Extraction for Quantitative Gene Expression Analysis}

Total RNA from cultured chondrocytes in different groups was extracted using TRI Reagent (Molecular Research Center, Cincinnati, OH) according to the manufacturer's instruction. Polyacryl Carrier (Molecular Research Center) was added in each extraction to precipitate the total RNA. Extracted RNA pellet was then washed with $75 \%$ ethanol and dried before dissolved in Rnase and Dnase free distilled water (Invitrogen, Carlsbad, CA). Yield and purity of the extracted RNA was determined by spectrophotometer (BioRad, Hercules, CA). Total RNA was stored at $-80^{\circ} \mathrm{C}$ immediately after extraction.

\section{Quantitative Gene Expression Analysis by Real-Time PCR}

Gene expression for chondrocytes differentiation (type II collagen and aggrecan core protein), dedifferentiation (type I collagen) and hypertrophy (type $X$ collagen) was quantitatively analyses with real-time PCR technique. The expression level of each targeted gene was then normalized to GAPDH. Primers for human GAPDH, type I, II, X collagen, aggrecan core protein were designed with Primer 3 software and blasted with GeneBank database sequences in order to obtain primers with high specificity. The efficiency and specificity of each primer set was confirmed with standard curve $(\mathrm{Ct}$ value versus serial dilution of total RNA) and melting profile evaluation. The primers sequences used in this study were as shown in Table 2. Real-time PCR reaction was performed with $100 \mathrm{ng}$ of total RNA, $400 \mathrm{nM}$ of each primer and iScript One-Step RT-PCR kit with SYBR Green (Bio-Rad) according to the manufacturer's instruction. Reactions were run using Bio-Rad iCycler with reaction profile of; cDNA synthesis for $30 \mathrm{~min}$ at $50^{\circ} \mathrm{C}$; pre-denaturation for $2 \mathrm{~min}$ at $94^{\circ} \mathrm{C}$; PCR amplification for 38 cycles with $30 \mathrm{sec}$ at $94^{\circ} \mathrm{C}, 30$ sec at $60^{\circ} \mathrm{C}$ and $30 \mathrm{sec}$ at $72^{\circ} \mathrm{C}$. This series of cycles was followed by a melt curve analysis to check the reaction specificity. Expression level of each targeted gene was normalized to GAPDH and chondrocyte differentiation index (the ratio of mRNA expression of type II collagen to type I collagen, CII/CI index) was then calculated for statistical analysis.

\section{Chondrocytes Culture for Cartilage Tissue Engineering}

Only culture media supplemented with $2 \% \mathrm{FBS}$ and growth factors ( $1 \mathrm{ng} / \mathrm{mL}$ bFGF $+1 \mathrm{ng} / \mathrm{mL}$ TGF- $\beta 2)$ were able to support high proliferation and provided sufficient number of cells for cartilage tissue engineering. In order to test the effects of ITS on the quality of engineered tissues, F12:DMEM + 2\%FBS + 1ng/mL bFGF + 1ng/ $\mathrm{mL}$ TGF- $\beta 2$ medium either added with ITS or without ITS was used as culture medium for large-scale chondrocyte culture in $175 \mathrm{~cm}^{2}$ culture flasks (Falcon) at 5,000 cells $/ \mathrm{cm}^{2}$ cell density. When confluence, the culture was trypsinized with $0.05 \%$ trypsin-EDTA (Gibco) and the harvested chondrocytes were suspended in a hydrogel as scaffold material for engineered tissue formation.

\section{Engineered Tissue Formation and Implantation}

Cultured chondrocytes were suspended into a 30\% (wt/ vol) of a co-polymer of polyethylene oxide and polypropylene oxide, Pluronic F-127 (BASF, Mount Olive, NJ) at $4^{\circ} \mathrm{C}$ with a cell density of $3 \times 10^{7}$ cells $/ \mathrm{mL}$. The resulted admixer was then injected subcutaneously at the dorsal part of the nude mice at 8 weeks of age under general anesthesia (ketamine, xylazil and zoletil). Care of the nude mice was carried out following the animal facility guideline of the Animal Unit, Institute of Medical Research Malaysia. 

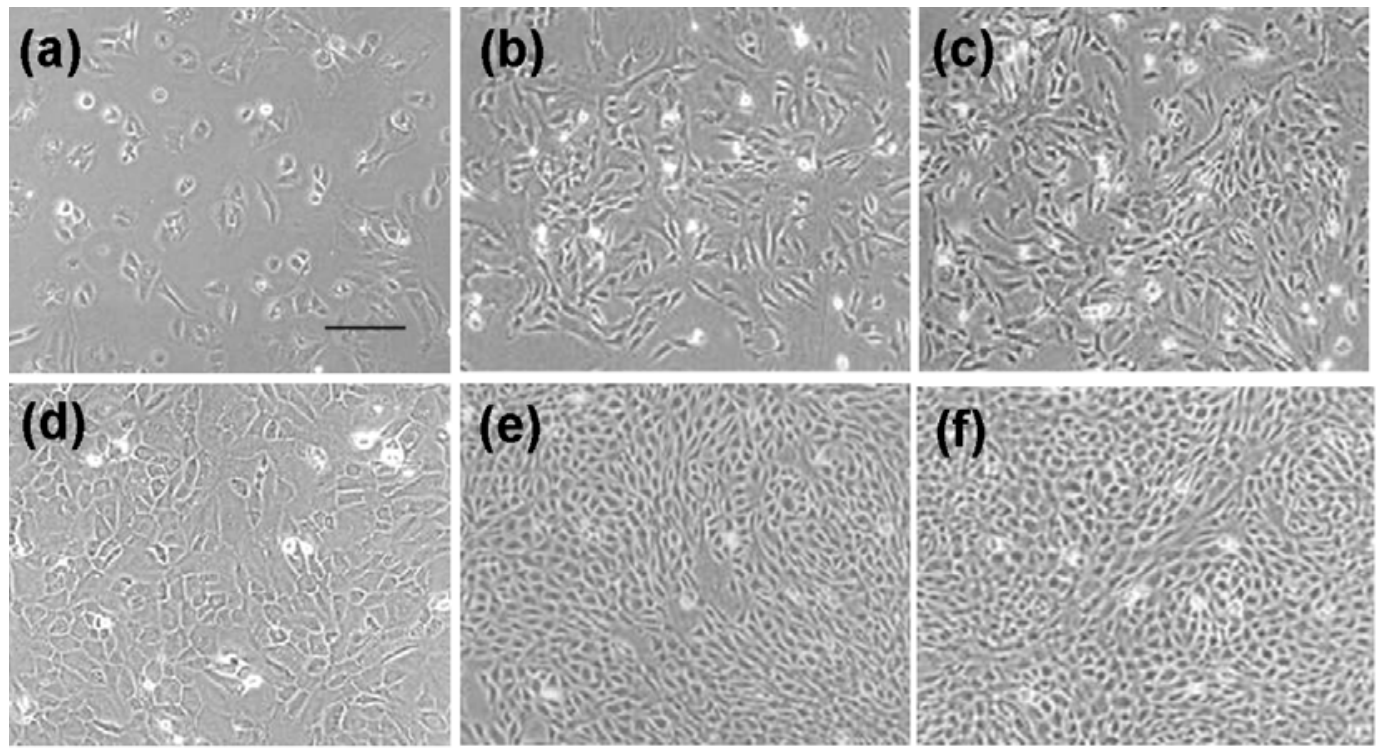

Figure 1: Human nasal septum chondrocytes primary culture (P0) for 10 days showed different morphologic feature in F12:DMEM supplemented with different factors. Same magnification was used in all pictures, bar scale equivalent to $0.1 \mathrm{~mm}$. (a) ITS. (b) $2 \% \mathrm{FBS}$. (c) ITS $+2 \%$ FBS. (d) GFs + ITS. (e) GFs $+2 \% \mathrm{FBS}$. (f) GFs + ITS $+2 \% \mathrm{FBS}$. ITS $=$ Insulin-transferrin-selenium. GFs $=1 \mathrm{ng} / \mathrm{mL}$ bFGF $+1 \mathrm{ng} / \mathrm{mL}$ TGF-b2.

\begin{abstract}
Harvest of the Engineered Tissues and Evaluation
The engineered tissues were harvested after 8 weeks of in vivo implantation. The nude mice were sacrificed by anesthetic overdose and engineered tissues were carefully dissected free from surrounding soft tissue. The engineered tissue was divided into two equal half with one part fixed in $10 \%$ phosphate buffered formalin (Fisher Scientific, Fair Lawn, NJ) and processed into paraffin embedded block. Paraffin blocks were then sectioned and the slides sections were stained with Hematoxylin \& Eosin (H\&E staining) and Safranin O staining. For immunohistochemical analysis on type II collagen production, slide sections were incubated with proteinase K (Sigma) at $37^{\circ} \mathrm{C}$ for 45 minutes. Mouse antihuman type II collagen antibody (sigma) at concentration of 1:100 was then applied on the section for 30 minutes follow by anti-mouse streptavidinperoxidase complex (Dako, Glostrup, Denmark) for 15 minutes and color development with DAB substrate (Dako) as chromogen. Another half of the excised tissue was digested with collagenase enzyme and total RNA was extracted for quantitative gene expression analysis as mentioned earlier. Native human nasal septum cartilage was use as normal control for comparison.
\end{abstract}

\section{Transmission Electron Microscopy}

Engineered tissues were cut into $1 \mathrm{~mm}^{3}$ blocks, fixed in $2.5 \%$ glutaraldehyde (Sigma) for 24 hours. Tissues blocks were then post-fixed in $1 \%$ osmium tetraoxide for 2 hours, dehydrated, infiltration with resin, embedding, ultra-thin sectioned, stained with $2 \%$ uranyl acetate and examined with CX-2000 transmission electron microscope (JEOL, Tokyo, Japan).

\section{Statistical Analysis}

Data for chondrocytes growth rate, number of cell doubling and viability in each medium at every passage (P0, P1, P2 and P3) were collected from six samples. Values were presented as mean \pm standard error of mean (SEM). ANOVA and Student's $t$ test was used to compare data between groups. Differences at the 5\% level were considered significant.

\section{Results}

\section{Cartilage Harvest and Chondrocytes Isolation}

The average wet weight of the human nasal septum cartilage harvested was $250 \pm 65 \mathrm{mg}$. The average isolated chondrocytes yield was $2.2 \times 10^{3} \pm 0.5 \times 10^{3}$ cells per mg of cartilage. Viability of the isolated chondrocytes was 94.2 $\pm 5.7 \%$.

\section{Chondrocytes Morphologic Feature in Monolayer Culture}

Human nasal septum chondrocytes cultured in F12:DMEM supplemented with various factors exhibited different morphologic feature in monolayer. Chondrocytes cultured in F12:DMEM with additional ITS showed minimal proliferation activity with only one or two cell doubling. Chondrocytes were relatively bigger and polygonal in shape on day 10 of primary culture (Figure 1a). Chondrocytes in this medium stopped proliferating after 2 weeks of primary culture and were unable to reach confluence. The culture was terminated without further passage.

Chondrocytes cultured in both F12:DMEM $+2 \% \mathrm{FBS}$ and F12:DMEM $+2 \%$ FBS + ITS were slow in proliferation and appeared polygonal in shape at primary culture (Figure 1b and 1c). Both cultures reached about $50 \%$ confluency on day 10 of primary culture. Medium added with ITS (Figure 1c) demonstrated higher cell density compared to medium added with only $2 \% \mathrm{FBS}$ 

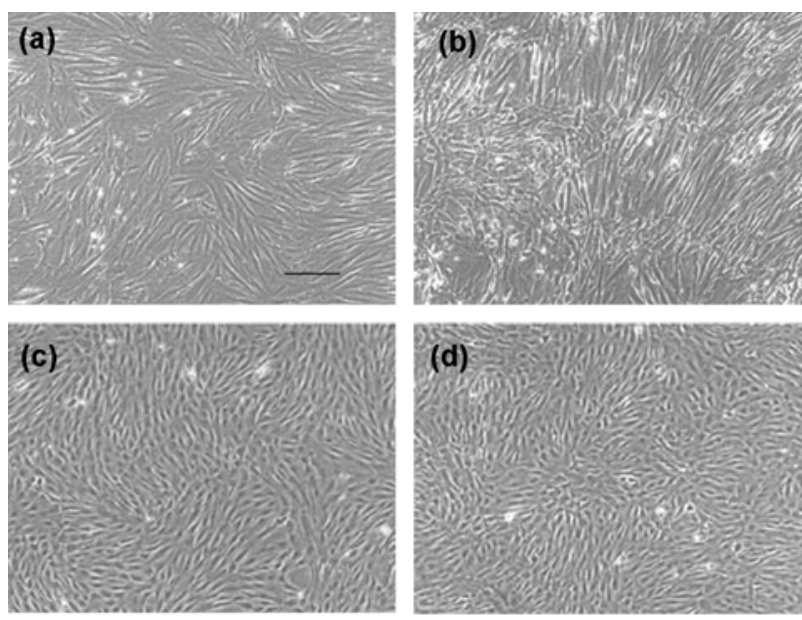

Figure 2: Human nasal septum chondrocytes culture at third passage (P3) for 10 days showed different morphologic feature in F12:DMEM supplemented with different factors. Same magnification was used in all pictures, bar scale equivalent to $0.1 \mathrm{~mm}$. (a) $2 \% \mathrm{FBS}$. (b) ITS $+2 \%$ FBS. (c) GFs $+2 \%$ FBS. (d) GFs + ITS + $2 \% \mathrm{FBS}$. ITS $=$ Insulin-transferrin-selenium. GFs $=$ $1 \mathrm{ng} / \mathrm{mL}$ bFGF + 1ng/mL TGF- $\beta 2$.

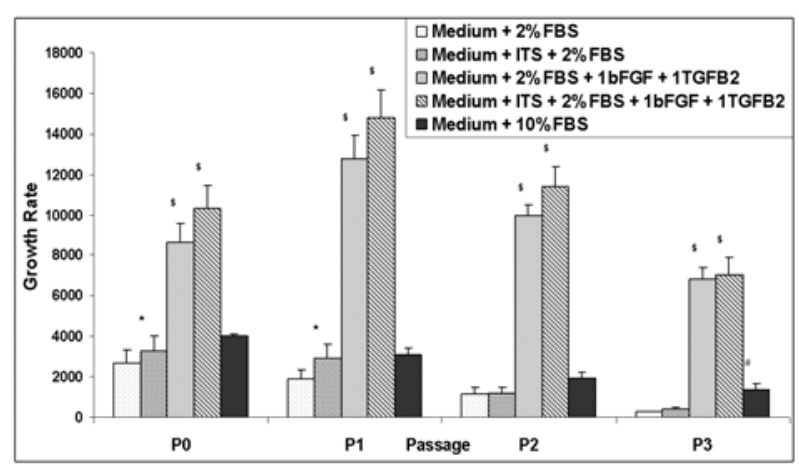

Figure 3: Growth rate (average increase in cell number per day $/ \mathrm{cm}^{2}$ ) of human nasal septum chondrocytes cultured in medium supplemented with different factors at primary culture (P0), passage $1(\mathrm{P} 1)$, passage 2 (P2) and passage 3 (P3). Values were showed as mean \pm SEM $(n=6)$. $\star$ Growth rate in medium + ITS + $2 \%$ FBS was significantly higher than medium + $2 \%$ FBS $(\mathrm{p}<0.05)$. \# Growth rate in medium $+10 \%$ FBS was significantly higher than medium $+2 \%$ FBS $(\mathrm{p}<0.05)$. \$ Growth rate in both media added with $1 \mathrm{ng} /$ $\mathrm{mL} b \mathrm{bGF}$ and TGF- $\beta 2$ were significantly higher than medium $+10 \%$ FBS $(\mathrm{p}<0.05)$. ITS $=$ Insulintransferrin-selenium.
(Figure 1b). Primary cultures in both media reached confluence at second week and were able to be passaged until the third passage (P3). Chondrocytes appeared more elongated in shape as it undergo passaged. At P3, chondrocytes were spindle and fibroblastic in shape, demonstrating the dedifferentiation morphology (Figure $2 \mathrm{a}$ and $2 \mathrm{~b}$ ). On day 10 of $\mathrm{P} 3$ culture, F12:DMEM $+2 \%$ FBS + ITS medium (Figure 2b) supported higher cell density compared to F12:DMEM + 2\%FBS medium (Figure 2a). Chondrocytes cultured in F12:DMEM supplemented with only $1 \mathrm{ng} / \mathrm{mL}$ bFGF $+1 \mathrm{ng} / \mathrm{mL}$ TGF- $\beta 2$ (GFs) did adhered on the culture plate, but were unable to proliferate. F12:DMEM + GFs + ITS supported better chondrocyte growth in primary culture and managed to reach confluence on day 10 of culture period (Figure1d). Chondrocytes in this medium appeared in polygonal shape and were relatively bigger compared to other cultures (Figure 1d). However, chondrocytes were unable to grow beyond P1 and the culture was terminated.

Chondrocytes cultured in both F12:DMEM + GFs + $2 \%$ FBS medium and F12:DMEM + GFs $+2 \%$ FBS + ITS medium adhered fast to the culture plate and demonstrated high mitotic activity. Chondrocytes cultured in both media were relatively smaller compared to other cultures and appeared polygonal in shape at primary culture (Figure 1e and 1f). Primary cultures in both media reached confluence on day 10 of culture and exhibited almost the same cell density (Figure 1e and 1f). Chondrocytes maintained high proliferation activity throughout the culture period until P3. Chondrocytes at P3 appeared slightly elongated in shape and remained small in size (Figure $2 \mathrm{c}$ and $2 \mathrm{~d}$ ).

\section{Expansion of Chondrocytes in Monolayer Culture} Human nasal septum chondrocytes cultured in F12:DMEM $+2 \%$ FBS medium and F12:DMEM $+2 \%$ FBS + ITS medium exhibited moderate growth rate (average increase in cell number per day $/ \mathrm{cm}^{2}$ ). Chondrocytes growth rate in both media decreased gradually from primary culture (P0) to third passage (P3) (Figure 3). F12:DMEM + 2\%FBS + ITS medium supported higher chondrocytes growth rate compared to F12:DMEM + 2\%FBS medium throughout the culture period but only significant $(\mathrm{p}>0.05)$ at $\mathrm{P} 0$ and $\mathrm{P} 1$ (Figure3). Chondrocytes growth rate in both media were lower than F12:DMEM + 10\%FBS medium as shown in Figure 3. However, the difference was only significant at P3.

Chondrocytes cultured in both media supplemented with $1 \mathrm{ng} / \mathrm{mL}$ bFGF, $1 \mathrm{ng} / \mathrm{mL}$ TGF- $\beta 2$ (GFs) and $2 \% \mathrm{FBS}$ demonstrated significant higher growth rate compare to other groups (Figure 3). Medium supplemented with GFs, $2 \%$ FBS and ITS exhibited the highest growth rate in the study. Chondrocytes growth rate in medium supplemented with GFs, $2 \%$ FBS and ITS was 2.6 times higher at P0, 4.8 times higher at $\mathrm{P} 1,5.8$ times higher at $\mathrm{P} 2$ and 5.2 times higher at P3 compare to medium $+10 \%$ FBS. Although addition of ITS in the medium consisted of GFs and $2 \%$ FBS increased chondrocytes growth rate, but no significant result was obtained when compared to medium without ITS supplementation (Figure 3). All cultures in the study scored viability greater than $90 \%$ and no significant difference was noted in the various groups.

Chondrocytes culture in F12:DMEM $+2 \%$ FBS medium from primary culture (P0) to passage 3 (P3) scored lowest cell doubling (7.0 of cell doubling) with only 132 fold increase in total cell number. With the addition of ITS (F12:DMEM $+2 \%$ FBS + ITS medium), chondrocyte culture from $\mathrm{P} 0$ to $\mathrm{P} 3$ scored higher cell doubling (8.1 cell doubling) with 271 fold increase in total cell number. F12:DMEM + 10\%FBS medium exhibited more cell doubling (scored 11.6 cell doubling) with 3,126 fold 
Table 3. Ratio of mRNA expression levels of type II to type I collagen (CII / CI) in human nasal septum chondrocytes monolayer culture (mean of six different specimens \pm SEM).

\begin{tabular}{lllll}
\hline Type of supplements & Primary culture (P0) & Passage 1 (P1) & Passage 2 (P2) & Passage 3 (P3) \\
\hline ITS & $11.98 \pm 2.84$ & $\mathrm{x}$ & $\mathrm{x}$ & $\mathrm{X}$ \\
$\mathbf{2 \% F B S}$ & $4.72 \pm 1.09$ & $0.094 \pm 0.024$ & $0.005 \pm 0.001$ & $0.0002 \pm 0.00005$ \\
* ITS + 2\%FBS & $9.79 \pm 1.79$ & $0.982 \pm 0.235$ & $0.168 \pm 0.061$ & $0.0068 \pm 0.0023$ \\
$\mathbf{1 0 \% F B S}$ & $2.23 \pm 0.71$ & $0.010 \pm 0.003$ & $0.0008 \pm 0.0002$ & $0.00006 \pm 0.00001$ \\
GFs & $1.60 \pm 0.53$ & $\mathrm{x}$ & $\mathrm{x}$ & $\mathrm{X}$ \\
ITS + GFs & $7.64 \pm 2.20$ & $0.071 \pm 0.024$ & $\mathrm{x}$ & $\mathrm{X}$ \\
$\mathbf{2 \% F B S}+$ GFs & $1.55 \pm 0.56$ & $0.015 \pm 0.004$ & $0.0017 \pm 0.0005$ & $0.0002 \pm 0.00005$ \\
" ITS + 2\%FBS + GFs & $5.86 \pm 2.00$ & $0.063 \pm 0.015$ & $0.0145 \pm 0.0041$ & $0.0029 \pm 0.0001$
\end{tabular}

* CII / CI index in ITS $+2 \%$ FBS group was significantly higher than $2 \%$ FBS group and $10 \%$ FBS group, $p<0.05$.

\# CII / CI index in ITS $+2 \% \mathrm{FBS}+$ GFs group was significantly higher than $2 \% \mathrm{FBS}+\mathrm{GFs}$ group and $10 \% \mathrm{FBS}$ group, $\mathrm{p}<0.05$.

FBS - fetal bovine serum; ITS $-10 \mu \mathrm{g} / \mathrm{mL}$ insulin $+5.5 \mu \mathrm{g} / \mathrm{mL}$ transferrin $+6.7 \mathrm{ng} / \mathrm{mL}$ sodium selenite; GFs $-1 \mathrm{ng} /$ $\mathrm{mL}$ basic fibroblast growth factor $+1 \mathrm{ng} / \mathrm{mL}$ transforming growth factor beta 2

increase in total cell number. Chondrocytes cultured in both media supplemented with $1 \mathrm{ng} / \mathrm{mL}$ bFGF and 1ng/ $\mathrm{mL}$ TGF- $\beta 2$ (GFs) scored the highest cell doubling from $\mathrm{P} 0$ to $\mathrm{P} 3$ compared to other groups. Culture in F12:DMEM $+\mathrm{GFs}+2 \% \mathrm{FBS}$ medium scored 15.3 cell doubling with 41,476 fold increase in total cell number and culture in F12:DMEM + GFs + 2\%FBS + ITS medium scored 15.5 cell doubling with 47,644 fold increase in total cell number.

\section{Quantitative Gene Expression of Human Nasal Septum Chondrocytes in Monolayer Culture}

In general, the mRNA expression level of type II collagen in various groups was decreased during passaging in contrast with type I collagen, which increased during passaging. This has contributed to the decrease of the ratio of mRNA expression levels of type II to type I collagen (CII / CI) in various groups during passaging (Table 3 ). The CII / CI index in ITS $+2 \%$ FBS group was significantly higher than both $2 \% \mathrm{FBS}$ group and $10 \% \mathrm{FBS}$ group in every passage (Table 3 ). In the growth factor supplemented groups, CII / CI index in ITS $+2 \% \mathrm{FBS}+$ GFs group was significantly higher than $2 \% \mathrm{FBS}+$ GFs group and $10 \%$ FBS group in every passage (Table 3 ). CII / CI index in the most proliferative group (ITS $+2 \% \mathrm{FBS}+\mathrm{GFs}$ ) was 2-fold higher at P0, 6-fold higher at P1, 18 fold higher at P2 and 48-fold higher at P3 when compared to the group supplemented with $10 \%$ FBS (Table 3 ). The mRNA expression level of aggrecan core protein was decreased during passaging in all groups (Table 4). Although addition of ITS into the culture medium increased the mRNA expression level of aggrecan core protein, no significant differences was noted when the mRNA expression level of aggrecan core protein in ITS $+2 \% \mathrm{FBS}$ group was compared to $2 \%$ FBS group as well as when ITS $+2 \%$ FBS + GFs group was compared to $2 \% \mathrm{FBS}+\mathrm{GFs}$ group. However, real-time PCR analysis showed ITS $+2 \%$ FBS + GFs group promoted significantly higher mRNA expression of aggrecan core protein compared to the

Table 4. Aggrecan core protein mRNA expansion of human nasal septum chondrocytes in monolayer culture normalized to GAPDH (mean of six different specimens \pm SEM).

\begin{tabular}{lcccc}
\hline Type of supplements & Primary culture (P0) & Passage 1 (P1) & Passage 2 (P2) & Passage 3 (P3) \\
\hline ITS & $0.042 \pm 0.007$ & $\mathrm{x}$ & $\mathrm{x}$ & $\mathrm{X}$ \\
$\mathbf{2 \% F B S}$ & $0.018 \pm 0.004$ & $0.0038 \pm 0.0013$ & $0.0007 \pm 0.0004$ & $0.0003 \pm 0.00004$ \\
ITS + 2\%FBS & $0.034 \pm 0.008$ & $0.0059 \pm 0.0014$ & $0.0009 \pm 0.0004$ & $0.0005 \pm 0.0002$ \\
$\mathbf{1 0 \% F B S}$ & $0.008 \pm 0.004$ & $0.0015 \pm 0.0002$ & $0.0005 \pm 0.0001$ & $0.0001 \pm 0.00003$ \\
GFs & $0.036 \pm 0.006$ & $\mathrm{x}$ & $\mathrm{x}$ & $\mathrm{X}$ \\
ITS + GFs & $0.069 \pm 0.012$ & $0.0053 \pm 0.0016$ & $\mathrm{x}$ & $\mathrm{X}$ \\
$\mathbf{2 \% F B S}+$ GFs & $0.027 \pm 0.006$ & $0.0023 \pm 0.0005$ & $0.0005 \pm 0.0001$ & $0.0002 \pm 0.00004$ \\
ITS + 2\%FBS + GFs & $\# 0.054 \pm 0.012$ & $\# 0.0049 \pm 0.0011$ & $0.0009 \pm 0.0002$ & $0.0003 \pm 0.0001$ \\
\hline
\end{tabular}

FBS - fetal bovine serum; ITS $-10 \mu \mathrm{g} / \mathrm{mL}$ insulin $+5.5 \mu \mathrm{g} / \mathrm{mL}$ transferrin $+6.7 \mathrm{ng} / \mathrm{mL}$ sodium selenite; GFs $-1 \mathrm{ng} /$ $\mathrm{mL}$ basic fibroblast growth factor $+1 \mathrm{ng} / \mathrm{mL}$ transforming growth factor beta 2

\# Significant higher Aggrecan core protein mRNA expression compared to $10 \%$ FBS group, $\mathrm{p}<0.05$. 


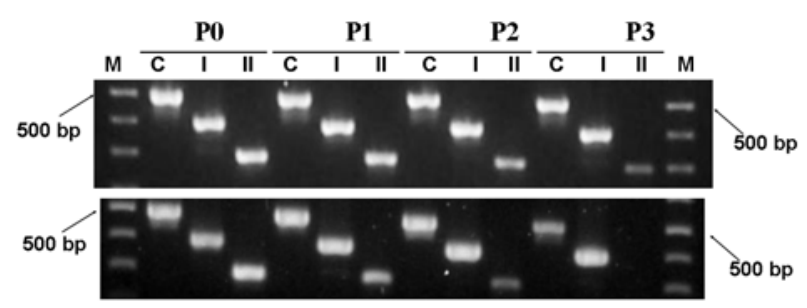

Figure 4: One step RT-PCR analysis on the gene expression of human nasal septum chondrocytes at primary culture $(\mathrm{P} 0)$, passage $1(\mathrm{P} 1)$ passage $2(\mathrm{P} 2)$ and passage 3 (P3). Chondrocytes cultured in medium supplemented with ITS (Top gel photo) showed higher expression of type II collagen gene compared with chondrocytes cultured in medium without ITS supplementation (Lower gel photo). Lane M: 100bp DNA marker. Lane C: $\beta$-actin gene fragment (Control; 495bp). Lane I: Type I collagen gene fragment (396bp). Lane II: Type II collagen gene fragment (294bp). ITS $=$ Insulin-transferrin-selenium.

medium added with $10 \%$ FBS at P0 (6.8-fold) and P1 (3.3fold). The chondrocyte hypertrophic marker, type $\mathrm{X}$ collagen, was either not detected or present in a very low level in real-time PCR analysis in all experimental groups.

\section{Histological Evaluation on Engineered Tissues}

Engineered tissues which were made by using the best medium for monolayer growth; F12:DMEM + GFs + $2 \% \mathrm{FBS}+$ ITS medium were glistening white in color and firm in consistency. Hematoxylin \& Eosin staining demonstrated the tissue consisted of evenly spaced lacunae cells embedded in a basophilic matrix (Figure 5a). The lacunae cells vary from round to oval shape with slight pleomorphism. Safranin O staining was positive, demonstrating the tissue was abundant in proteoglycans production (Figure 5c). A fibrous capsule resembling perichondrium surrounded the engineered tissue was also noted.

Engineered tissues resulted from medium without ITS supplementation (F12:DMEM + GFs $+2 \%$ FBS medium) exhibited slightly more translucent in appearance compared to tissues resulted from ITS supplementation. Hematoxylin $\&$ Eosin staining demonstrated the presence of immature lacunae cells with reactive nucleus in the tissue (Figure $5 b)$. Safranin O staining showed less area of positive staining, correlating with less proteoglycans production in the tissue (Figure 5d).

Immunohistochemical staining for type II collagen demonstrated positive staining in the matrix of engineered tissues that consisted of lacunae cells (both with and without ITS supplementation after 8 weeks of implantation, Figure 6).

\section{Transmission Electron Microscopy Examination}

Transmission electron micrographs showed cells in the engineered tissues resulted from F12:DMEM + GFs + $2 \%$ FBS + ITS culture medium were cuboidal in shape with
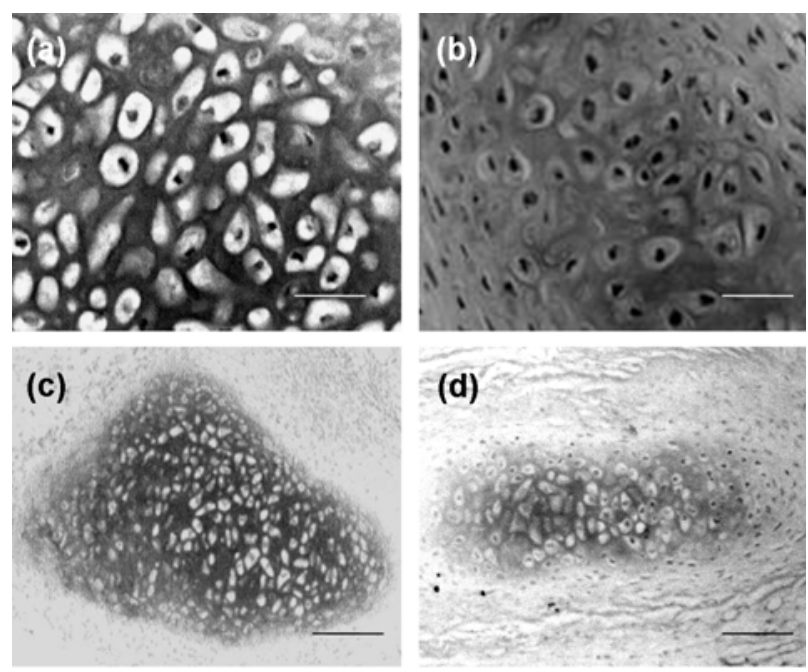

Figure 5: Histological sections of engineered tissues stained with Hematoxylin \& Eosin (a) \& (b) and Safranin O (c) \& (d). Bar scale in picture (a) \& (b) is $30 \mu \mathrm{m}$. Bar scale in picture (c) \& (d) is $0.1 \mathrm{~mm}$. Engineered tissue resulted from medium supplemented with $1 \mathrm{ng} / \mathrm{mL}$ bFGF $+1 \mathrm{ng} / \mathrm{mL}$ TGF- $\beta 2$ $+2 \%$ FBS + ITS (a \& c) demonstrated better quality compared to engineered tissue resulted from medium without ITS supplementation ( $b$ \& d). ITS = Insulintransferrin-selenium.

cytoplasm processes extended into the extracellular matrix (Figure 7a). The cells were rich with mitochondria and endoplasmic reticulum for protein production. The presence of abundant collagen fibrils was noted as the major component in the extracellular matrix. Ultrastructure of the cells in engineered tissue resulted from medium without ITS supplementation was elongated in shape with reaction nucleus, demonstrating fibroblastic and immature cell characteristic (Figure 7b).

\section{Quantitative Gene Expression in Tissue Engineered Cartilage}

Tissue engineered cartilage without ITS supplementation expressed 9.2-fold higher type I collagen and 2.9-fold higher type II collagen but 2.4-fold lower type X collagen and 5.2-fold lower aggrecan core protein mRNA compared to native human nasal septum cartilage (Table 5). Tissue engineered cartilage without ITS supplementation scored 3.4 fold lower CII/CI index compared to native human nasal septum cartilage. Tissue engineered cartilage with ITS supplementation expressed 7.8-fold higher type I collagen and 4-fold higher type II collagen but 2-fold lower type $\mathrm{X}$ collagen and aggrecan core protein mRNA compared to native human nasal septum cartilage (Table 5). Tissue engineered cartilage with ITS supplementation scored 2.1-fold lower CII/CI index compared to native human nasal septum cartilage. ITS supplementation has resulted significant higher mRNA expression of type II collagen, aggrecan core protein and higher CII/CI index in tissue engineered cartilage formation (Table 5). 


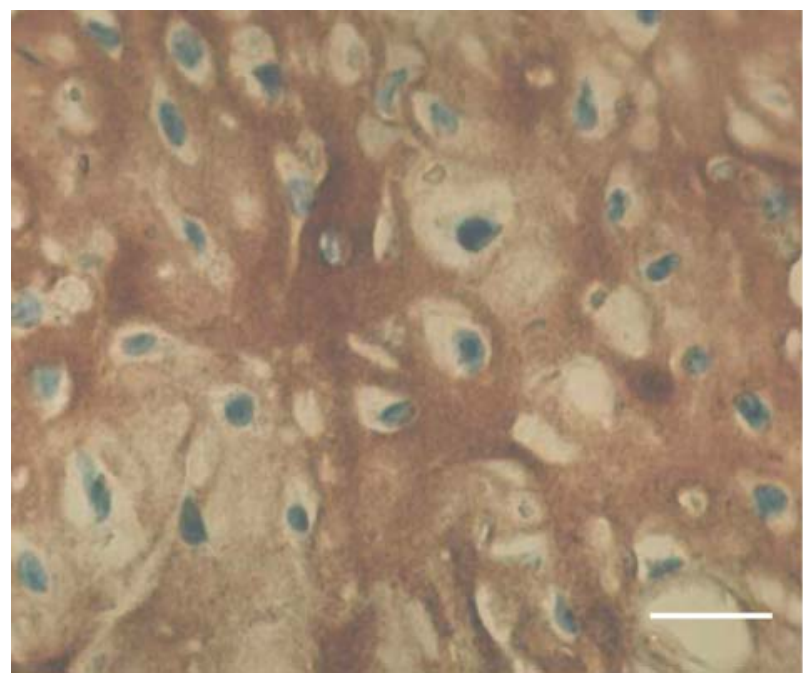

Figure 6: Immunohistochemical staining of type II collagen on the section of engineered tissues showed positive staining in the matrix. Bar scale $30 \mu \mathrm{m}$.
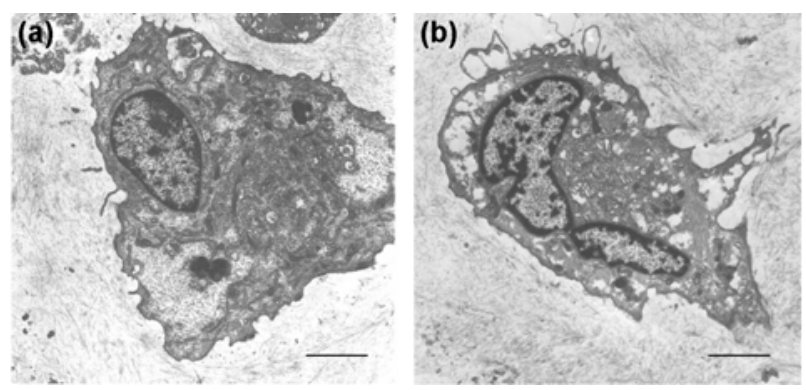

Figure 7: Transmission electron micrographs showed cells in the engineered tissues resulted from medium added with ITS was cuboidal in shape (a) compared to cells in engineered tissues resulted from medium without ITS was more elongated (b). Ultra-structure sections demonstrated cell cytoplasm processes extended into the extracellular matrix and abundant fibril collagen secretion. Bar scale $5 \mu \mathrm{m}$.

\section{Discussion}

Tissue engineering technology offers an approach in constructing autologous graft for transplantation starting from a minimal donor tissue from the same patient. The amount of chondrocytes that can be harvested from patient's own nasal septum is too limited in number for the construction of a new graft for the transplantation purpose. A culture medium, which consists of essential factors for the efficient propagation of human chondrocyte is necessary to make this technology more viable for future clinical application. We showed that human chondrocytes were unable to grow in serum free medium either supplemented with ITS or with the growth factors, $1 \mathrm{ng} /$ $\mathrm{mL}$ bFGF plus 1ng/mL TGF- $\beta 2$ (GFs). Supplementation of $2 \% \mathrm{FBS}$ in the culture medium (F12:DMEM $+2 \% \mathrm{FBS})$ allowed chondrocyte to grow until P3. This minimum amount of serum has provided essential growth agents for human chondrocytes to proliferate. Higher serum supplementation in the medium (F12:DMEM + 10\%FBS) supported higher growth rate and provided 24 times higher total cell number compared to $2 \% \mathrm{FBS}$ medium. This serum stimulation effect was also reported by other studies on human articular chondrocytes (Choi et al., 1980; Hu et al., 2002). However, the addition of serum also caused chondrocytes to change its morphologic features to become more fibroblastic and dedifferentiate in the monolayer culture as demonstrated by the real-time PCR analysis. The commercially available ITS used in this study was formulated for the purpose of supporting cell growth in low serum culture medium. Our results showed that supplementing ITS in $2 \%$ FBS culture medium was able to further enhance chondrocyte growth and significantly reduced the dedifferentiation process of cultured chondrocytes by demonstrating higher index of CII/CI and higher mRNA expression of aggrecan core protein. Although ITS $+2 \%$ FBS culture medium enable the chondrocyte number to double compared to medium added with $2 \%$ FBS only, the amount of chondrocytes harvested from this culture medium is still inadequate for constructing an engineered cartilage.

A more efficient culture medium, which contain 1ng/ $\mathrm{mL}$ bFGF, $1 \mathrm{ng} / \mathrm{mL}$ TGF- $\beta 2$ (GFs) and $2 \% \mathrm{FBS}$ has dramatically increased human chondrocytes growth rate

Table 5. Quantitative gene expression in native human nasal septum cartilage and tissue engineered cartilage (mean of six different specimens \pm SEM).

\begin{tabular}{llllll}
\hline Type of tissues & Type I collagen & Type II collagen & $\begin{array}{l}\text { C II / C I } \\
\text { Index }\end{array}$ & Type X collagen & $\begin{array}{l}\text { Aggrecan core } \\
\text { protein }\end{array}$ \\
\hline $\begin{array}{l}\text { Nasal septum } \\
\text { cartilage }\end{array}$ & $0.013 \pm 0.002$ & $1.66 \pm 0.05$ & $143.1 \pm 19.6$ & $0.012 \pm 0.006$ & $0.745 \pm 0.150$ \\
$\begin{array}{l}\text { Engineered } \\
\text { tissue without } \\
\text { ITS }\end{array}$ & $0.120 \pm 0.010$ & $4.79 \pm 0.06$ & $42.7 \pm 5.2$ & $0.0049 \pm 0.0022$ & $0.142 \pm 0.024$ \\
$\begin{array}{l}\text { Engineered } \\
\text { tissue + ITS }\end{array}$ & $0.101 \pm 0.011$ & $* 6.56 \pm 0.12$ & $* 68.3 \pm 7.6$ & $0.0057 \pm 0.0025$ & $* 0.371 \pm 0.071$ \\
\hline
\end{tabular}

* Significant higher value in engineered tissue + ITS compared to engineered tissue without ITS supplementation, $\mathrm{p}<0.05$. 
in the monolayer culture. Our study has showed the beneficial effects of supplementing both bFGF and TGF$\beta 2$ by providing sufficient chondrocytes for engineered cartilage construction compared to the conventional culture medium. The growth factors supplemented medium has provided sufficient number of chondrocytes for tissue engineered cartilage formation. The growth stimulation effect by both growth factors on chondrocytes has also been reported by Bujia et al. (1994; human nasal septal chondrocytes) and de Haart et al. (1999; bovine articular chondrocytes) in $10 \%$ fetal calf serum supplemented medium. However, supplementation of both growth factors into the culture medium also has caused the cultured chondrocytes to lose the differentiation property in a faster rate. Our results showed that the addition of ITS into the culture medium was necessary to reduce the chondrocyte dedifferentiation process (higher index of CII/CI and higher mRNA expression of aggrecan core protein) although the growth promoting effects of ITS was not prominent in the presence of both growth factors. Cultured chondrocytes in all our experiment groups did not show the tendency of being hypertrophy in the monolayer culture.

Since the cultured chondrocytes from ITS $+2 \% \mathrm{FBS}+$ GFs medium retained better differentiation property during monolayer culture, these has resulted better quality of tissue engineered cartilage formation after 8 weeks of implantation in the nude mice model. Grossly, the harvested engineered cartilage resulted from ITS supplemented medium was larger and exhibited more cartilage-like appearance. Results from the histological analysis of the tissue engineered cartilage confirmed that the tissue consisted of lacunae cells with abundant proteoglycans production resembling human native cartilage. Immunohistochemical staining of the tissue engineered cartilage also demonstrated the presence of human type II collagen in the engineered tissues matrix surrounding the lacunae cells. The ultra-structure features of the lacunae cells in the engineered tissues showed active protein synthesis with abundant collagen fibrils secreted into the extracellular space. Results from the quantitative gene expression analysis demonstrated the engineered cartilage with ITS supplementation have not fully developed into mature cartilage. The tissues showed high mRNA expression of both type I collagen and type II collagen and with the differentiation index and aggrecan core protein mRNA level that is still lower than the native human nasal septum cartilage. Tissue engineered cartilage in this study did not show tendency of being hypertrophy since type $\mathrm{X}$ collagen was detected at a low level. Real-time PCR results also verified that ITS supplementation resulted in higher quality of engineered cartilage formation by scoring higher differentiation index. Engineered cartilage resulted from medium without ITS supplementation has demonstrated either neocartilage or fibrocartilage formation in the histological and transmission electron microscopy evaluation. The engineered cartilage without ITS supplementation consisted of immature lacunae cells with more elongated shape and less cartilage proteoglycans production. However, these engineered cartilage may develop into a mature and functional cartilage with longer period of in vivo implantation.
In this study, F12:DMEM supplemented with 2\%FBS, ITS, $1 \mathrm{ng} / \mathrm{mL}$ bFGF and $1 \mathrm{ng} / \mathrm{mL}$ TGF- $\beta 2$ has provided valuable implications on constructing human cartilage graft for clinical implantation in head and neck reconstructive surgery such as for the repair of nasal bridge, trachea and ear. This medium has reduced the risk of immune reaction against engineered tissue by reducing the amount of animal serum used in the medium from $10 \%$ to $2 \%$. It also provided the starting step for further studies on formulating a serum free medium for human chondrocyte monolayer expansion.

\section{Conclusion}

Our study has concluded that Insulin-transferrin-selenium with $2 \%$ serum supplementation in the medium can promoted higher chondrocyte growth rate and better differentiation properties in monolayer culture either with or without additional of recombinant growth factors. $\mathrm{F} 12: \mathrm{DMEM}+\mathrm{ITS}+2 \% \mathrm{FBS}+1 \mathrm{ng} / \mathrm{mL} \mathrm{bFGF}+1 \mathrm{ng} / \mathrm{mL}$ TGF- $\beta 2$ medium could provide large number of chondrocytes in shorter period of time compared to the conventional medium supplemented with $10 \%$ serum. Engineered cartilage resulted from this medium demonstrated higher quality in morphological appearance, histological analysis, ultra-structure examination and quantitative gene expression evaluations. Our results suggested that ITS should be added into human chondrocytes monolayer culture for the production of higher quality engineered cartilage for future clinical application.

\section{Acknowledgements}

This study is made possible by 06-02-02-003 BTK/ER/ 022 and IRPA 06-02-02-0037-EA189 grants from the Ministry of Science, Technology and Innovation of Malaysia, Hospital Universiti Kebangsaan Malaysia and Medical Faculty, Universiti Kebangsaan Malaysia.

Special thanks to Mr. Megat Radzi MAR for his assistance in electron microscopic works at Electron Microscope Unit, Universiti Kebangsaan Malaysia.

\section{References}

Bujia J, Sittinger M, Wilmes E, Hammer C (1994) Effects of growth factors on cell proliferation by human nasal septal chondrocytes cultured in monolayer. Acta Otolaryngol 114: 539-543.

Cao YL, Rodriguez A, Vacanti M, Ibarra C, Arevalo C, Vacanti CA (1998) Comparative study of the use of polyglycolic acid, calcium alginate and pluronic in the engineering of autologous porcine cartilage. J Biomater Sci Polymer Ed 5: 475-487.

Choi YC, Morris GM, Lee FS, Lee FS, Sokoloff L (1980) The effect of serum on monolayer cell culture of mammalian articular chondrocytes. Connect Tissue Res 7:105-112. 
de Haart M, Marijnissen WJ, van Osch GJ, Verhaar JA (1999) Optimization of chondrocyte expansion in culture. Effect of TGF $\beta-2$, bFGF and L-ascorbic acid on bovine articular chondrocytes. Acta Orthop Scand 70: 55-61.

Harrington WN, Godman GC (1980) A selective inhibitor of cell proliferation from normal serum. Proc Natl Acad USA 77: 423-427.

Homicz MR, Chia SH, Schumacher BL, Masuda K, Thonar EJ, Sah RL, Watson D (2003) Human septal chondrocyte redifferentiation in alginate, polyglycolic acid scaffold, and monolayer culture. Laryngoscope 113(1): 25 32.

Homicz MR, Schumacher BL, Sah R, Watson D (2002). Effects of serial expansion of septal chondrocytes on tissueengineered neocartilage composition. Otolaryngol Head Neck Surg 127: 398-408.

$\mathrm{Hu}$ DN, Yang PY, Ku MC, Chu CH, Lim AY, Hwang MH (2002) Isolation and cultivation of human articular chondrocytes. Kaohsiung J Med Sci 18:113-120.

Loty S, Sautier JM, Forest N (2000) Phenotypic modulation of nasal septal chondrocytes by cytoskeleton modification. Biorheology 37:117-125.

Mandl EW, Van Der Veen SW, Verhaar JA, Van Osch GJ (2002) Serum-free medium supplemented with highconcentration FGF2 for cell expansion culture of human ear chondrocytes promotes redifferentiation capacity. Tissue Eng 8: 573-580.

Olney RC, Wang J, Sylvester JE, Mougey EB (2004). Growth factor regulation of human growth plate chondrocyte proliferation in vitro. Biochem Biophys Res Commun 317: 1171-1182.

Pei M, Seidel J, Vunjak-Novakovic G, Freed LE (2002) Growth factors for sequential cellular de- and redifferentiation in tissue engineering. Biochem Biophys Res Commun 294: 149-154.

Rotter N, Bonassar LJ, Tobias G, Lebl M, Roy AK, Vacanti CA (2001) Age dependence of cellular properties of human septal cartilage: implications for tissue engineering. Arch Otolaryngol Head Neck Surg 127: 12481252.

Saim AB, Cao Y, Weng Y, Chang CN, Vacanti MA, Vacanti CA, Eavey RD (2000) Engineering autogenous cartilage in the shape of a helix using an injectable hydrogel scaffold. Laryngoscope 110: 1694-1697. van Osch GJ, van der Veen SW, Verwoerd-Verhoef HL (2001) In vitro redifferentiation of culture-expanded rabbit and human auricular chondrocytes for cartilage reconstruction. Plast Reconstr Surg 107: 433-440.

\section{Discussion with Reviewers}

F. Mwale: Would the levels of proteoglycan and collagen contents be similar to native cartilage levels? This is the minimum requirement for the formation of a "high quality tissue engineered human hyaline cartilage".

Authors: The quantitative mRNA expression results showed that the engineered cartilage has not reached the fully mature level as compared to the native cartilage, since both type I and type II collagen mRNA were expressed at higher levels compared to the native cartilage. However, ITS supplementation did promote the production of higher quality engineered cartilage.

F. Mwale: It is not clear why TGF- $\beta 2$ was used? Would TGF- $\beta 1$ have similar effects?

Authors: TGF- $\beta 2$ was used because it is more potent than other members in the same family (Olney et al., 2004). Thus, we did not use TGF- $\beta 1$.

F. Mwale: The authors describe the morphology of the cells grown under different conditions in detail, but do not explain what constitutes the desired morphology. It is also not clear what the EM micrograph adds to the paper.

Authors: Chondrocytes appeared in polygonal shape at differentiation state (early culture) and became elongated when dedifferentiated, changing it to fibroblastic-like characteristic. EM micrograph was used to describe the ultra-structural organization and extra-cellular matrix arrangement in engineered cartilage with or without ITS supplementation.

F. Mwale: Do the authors envisage a paracrine effect in the nude mice?

Authors: The experiment on paracrine effect in the nude mice was not done. 